\title{
IMPACT OF ANXIETY AND TERROR OF DEATH ON QUALITY OF LIFE IN PATIENTS ON CHRONIC HEMODIALYSIS

\author{
Olha Shevchuk-Kravchenko ${ }^{1}$, Oksana Penderetska ${ }^{2}$, Ivan Garazdiuk ${ }^{3}$,
} Oleksandr Garazdiuk ${ }^{4}$, Viktor Bachynskiy ${ }^{5}$
}

\begin{abstract}
The aim of the study was to identify the terror of death and anxiety level in patients with end-stage renal disease receiving renal replacement therapy using chronic hemodialysis (HD) and to evaluate the impact of patients' psychological status on medical staff, selection of basic methods of psychotherapeutic care for patients in this category. We involved 37 patients, aged 33-72 years (mean, $45.6 \pm 3.8$ years). The duration of chronic HD ranged from 8 months to 10 years, with an average of 4.6 years. All the patients had a stable nutritional status, HD regimen and drug therapy for at least 3 months. To diagnose the psychological state of patients we used: the scale of self-assessment of the level of situational and personal anxiety (Spielberger-Hanin's Scale), personal questionnaire for changes at the onset of HD therapy, elements of a clinical interview, image apperception test (simplified version of Thematic apperception test., Bechterev's Institute Personal Questionnaire for Diagnosis of Type of Illness (LOBI), Locus of control and personal changes after initiation of HD therapy.

We found that the: adaptation of the patient to HD therapy is complicated due to the high degree of anxiety and maladaptive terror of death, which reduce the patient's quality of life. The HD procedure increases the level of situational anxiety and requires psycho-correction. HD therapy requires activation of the patient's psychological protection mechanisms, since the dominant protective mechanisms of the psyche in this type of substitution treatment are displacement and negation. The inflexible and rigid use of the latter provokes maladaptive reactions when interacting with healthcare providers, a nonconstructive approach to lifestyle choices, work-rest regime, and diet. Patients with a maladaptive mode of adjustment to HD therapy require psychotherapy assistance. There is a need to monitor the psychological status of not only patients, but also medical staff, which due to the specificity of the contingent increases the level of contingent own terror of death. Doctors of HD units require participation in mutual support groups.
\end{abstract}

UDC Classification: 616-052, 616-051, DOI: https://doi.org/10.12955/pmp.v1.105

Keywords: anxiety, hemodialysis, terror of death, quality of life, burnout

\section{Introduction}

Treatment of patients with chronic renal insufficiency using chronic hemodialysis (HD) is a potent psycho-traumatic factor and requires adequate mechanisms of defense (McClellan et al., 1991). The psycho-traumatic factors include: regular stay of patients in the environment with a heightened level of morbidity and emergence of intrapersonal conflict due to dependence on HD (El Filali et al., 2017). Undiagnosed neurotic and depressive disorders accompany somatic pathology in 50-60\% of patients (Roeh et al., 2019). Functional status and quality of life are strong independent risk factors for subsequent mortality in new dialysis patients (McClellan et al., 1991). The presence of mental disorders not only significantly reduces the quality of life of such patients, it adversely affects their somatic condition and also provokes the enhancement of psychological disorders in medical staff in the process of the interpersonal relationship (Lee \& King, 2014).

The medical staff of the department of chronic HD referred to the conditions of work as extreme, and higher stress levels on the medical staff of this department is comparable with intensive care units and hospices (Javadi-Pashaki \& Darvishpour, 2019).

The aim of the study. The aim of the study was to identify the terror of death and anxiety level in patients with end-stage renal disease receiving renal replacement therapy using chronic HD and to evaluate the impact of patients' psychological status on medical staff, selection of basic methods of psychotherapeutic care for patients in this category and the actualization of medical necessity knowledge about the psychological characteristics of patients of this contingent.

We were assigned the following tasks:

1. To evaluate the type of internal presentation of the disease;

2. To describe the protective mechanisms of the psyche, which are activated under the influence of treatment by chronic HD;

\footnotetext{
${ }^{1}$ Bukovinian State Medical University, Chernivtsi, Ukraine, pk@bsmu.edu.ua

${ }^{2}$ Bukovinian State Medical University, Chernivtsi, Ukraine, pk@bsmu.edu.ua

${ }^{3}$ Bukovinian State Medical University, Chernivtsi, Ukraine, i.harazdiuk@bsmu.edu.ua

${ }^{4}$ Bukovinian State Medical University, Chernivtsi, Ukraine, garazdyuk.olexandr@bsmu.edu.ua

${ }^{5}$ Bukovinian State Medical University, Chernivtsi, Ukraine, sudmed@bsmu.edu.ua
} 
3. To determine the locus of control;

4. To actualize among medical professionals the need for knowledge about the psychological characteristics of patients of this contingent.

Material and methods. The study was conducted at the department of chronic HD of Chernivtsi Regional Clinical Hospital. 37 patients, aged 33-72 years (mean, 45.6 \pm 3.8 years), participated in psychodiagnosis. Women comprised $45.94 \%$ - 17 people, men $-54.06 \%$ - 20 people; the duration of chronic HD treatment at the time of the survey ranged from 8 months to 10 years, with an average of 4.6 years. The study group included patients who had a stable nutritional status, HD regimen and drug therapy for at least 3 months.

To diagnose the psychological state of patients the following methods were used:

1. The scale of self-assessment of the level of situational and personal anxiety (Spielberger-Hanin's scale (Spielberger, 1983)). This test is a reliable and informative way to self-assess the level of anxiety at a particular moment (reactive, situational) and personal anxiety, as a stable characteristic of personality.

2. Personal questionnaire for changes at the onset of HD therapy, elements of a clinical interview. The questionnaire was used to diagnose terror of death in patients. The survey was conducted for differential diagnosis with anxiety and to determine the psycho-corrective feasibility of thematic interventions. The questionnaire was created on the basis of the Personal Changes Questionnaire in Breast Cancer Patients (Yalom, 1980).

3. Image apperception test (simplified version of Thematic apperception test (Aronow et al., 2013)). The technique gives an opportunity to identify deep internal conflicts and features of mechanisms of adaptation to them. We have adapted the methodology to the conditions and objectives of the study. The emphasis is placed on the study of personality as a whole, which involves the primary version of the methodology, on the study of mechanisms of personal protection.

4. Bechterev's Institute Personal Questionnaire for Diagnosis of Type of Illness (LOBI), related interpersonal relationships and vital functions, which allows us to study the conscious component of the type of illness (Lichko, 1983).

The use of the above mentioned techniques allowed us to consider the problems of mechanisms of protection from the standpoint of conscious and unconscious processes.

5. To evaluate the degree of adaptive constructiveness, we used locus of control and personal changes after initiation of HD therapy. To achieve this goal, the methodology of the study of the level of subjective control of J. Rotter (adaptation of Bazhin EF, Golinkina SA, Etkida AM(Wallston et al., 1976)) was used, and it is possible to determine the locus of control.

\section{Definition of concepts}

Anxiety is the experience of emotional discomfort associated with the expectation of distress, a sense of danger. Unlike terror, as a reaction to a specific real danger, anxiety is an experience of vague, diffuse, unbiased threat. From the physiological side - the autonomic nervous system is activated. They distinguish situational and personal anxiety. Situational anxiety is psychogenic, that is, one that arises after or directly during psycho-traumatic events. Personal anxiety is a part of the personality structure and is its characteristic feature (Yalom, 1980).

Fear of death is a kind of terror in the awareness of the "instant of being" (Kierkegaard), of "impossibility of further possibility" (Heidegger), of "ontological anxiety" (Tillich) (Yalom, 1980). Jacques Horon distinguishes three types of terror of death: the terror of what will come after death, the terror of the actual event of dying and the terror of ending life. The clinician rarely faces the terror of death in its entirety, as it is modified by standard protection mechanisms. However, a clinician who develops an "existential setting" will be able to recognize the terror of death even in a "fulfilled form" (Yalom \& Lieberman, 1991)

Psychological protection (psychological adaptation) is a system of regulatory mechanisms in the psyche that are aimed at eliminating or minimizing negative, traumatic personality experiences, combined with internal or external conflicts, anxiety and discomfort (Zamanayeva \& Frumkin, 2005). 
An internal picture of a disease (a type of attitude to illness) is a patient's attitude to illness, which includes a set of emotional, cognitive and behavioral responses related to its occurrence and course (Yalom \& Lieberman, 1991).

Locus of control is a way (strategy) when a person attributes causality and responsibility for the results of his or her own activities. There are 2 polar types of localization of the locus of control: external and internal. In the first case, a person believes that the events that occur to him are the result of external forces - the case, other people, etc. In the second case, the individual interprets significant events as a result of his or her own activity (Wallston et al., 1976).

\section{Results of the research and discussion}

\section{Self-esteem scale of situational and personal level}

Spielberger-Hanin's scale (Spielberger, 1983).

We have found $25(67.57 \%)$ patients were diagnosed with high levels of personal anxiety, $10(27.03 \%)$ were moderate, $2(5.40 \%)$ were low. In $34(91.89 \%)$ of patients a high level of situational anxiety was diagnosed, in 3 (8.11) \% - moderate during the HD procedure (Table 1). It should be noted that no patient was found to have a low level of situational anxiety, even with low personal anxiety in $5.40 \%$ of cases. All patients who demonstrated low levels of personal anxiety were diagnosed with a normal level of situational anxiety. In cases of normal and high levels of personal anxiety, a high level of situational anxiety was diagnosed during the HD procedure. This testifies to the psycho-traumatic course of the HD procedure.

\begin{tabular}{|l|l|l|c|c|}
\hline Table 1: Assessment of situational and personal anxiety level in HD patients \\
\hline \multirow{5}{*}{} & \multicolumn{3}{|c|}{ Level of anxiety $(\mathbf{n = 3 7})$} \\
\cline { 2 - 5 } & Type of anxiety & High & Moderate & Low \\
\cline { 2 - 6 } & Situational & $34(91.89 \%)$ & $3(8.1 \%)$ & 0 \\
\cline { 2 - 6 } & Personal & $25(67.57 \%)$ & $10(27.03 \%)$ & $2(5.40 \%)$ \\
\hline Source: Authors
\end{tabular}

We suggest the high level of personal anxiety may be a "mask" of the terror of death (Yalom, 1980). Therefore, we have used in the study A Personal Changes Questionnaire designed to examine breast cancer patients and adapted by us for this category of patients (Yalom \& Lieberman, 1991).

\section{Questionnaire on personal changes after initiation of HD therapy}

According to Jacques Horon, (cited by Yalom (1980)) the terror of death has three manifestations: the terror of the process of dying, the terror of dead people, and the terror of what will be after death. Therefore, taking this into account, we modified the questionnaire proposed by I. Yalom, 1980. The questionnaire contained a number of traits from different types of perceptions and interpersonal communication. Inside the questionnaire was a statement of terror of death. Patients were asked to evaluate the severity of these features after initiating HD therapy. Overall, $70 \%$ of patients reported an increase in terror of death in its various manifestations (Table 2).

- $\quad 20(54.05 \%)$ of patients became more afraid of "what awaits them after death",

- $\quad 3(8.11 \%)$ - the " the process of dying ",

- $3(8.11 \%)$ patients said that after the start of HD therapy, dead people became more afraid.

Table 2: Manifestations of terror of death in HD patients after initiation of HD session

\begin{tabular}{|c|c|c|c|}
\hline \multirow[b]{2}{*}{ Changes in terror of death level } & \multicolumn{3}{|c|}{ Manifestations of patient's terror of death $(n=37)$} \\
\hline & $\begin{array}{c}\text { "what awaits them } \\
\text { after death" }\end{array}$ & $\begin{array}{c}\text { "the process of } \\
\text { dying" }\end{array}$ & "dead people" \\
\hline Increased & $20(54.05 \%)$ & $3(8.11 \%)$ & $3(8.11 \%)$ \\
\hline Decreased & $4(10.82 \%)$ & $9(24.32 \%)$ & $12(32.43 \%)$ \\
\hline Unchanged & $13(35.13 \%)$ & $25(67.57 \%)$ & $22(59.46 \%)$ \\
\hline
\end{tabular}

Source: Authors

\section{A personal questionnaire from the Bechterev's Institute}

Traditionally, it is believed that with the help of a certain internal picture of the disease it is possible to detect in the somatic patient the prevailing emotional state, quality of life, presence and importance of professional activity and even to diagnose compliance with medical recommendations (Zamanayeva \& 
Frumkin, 2005). However, in some cases it is not possible to diagnose a certain type of internal picture of the disease (lack of diagnostic criteria in patients). The same situation happened in our study.

The prevalence of this or that type of disease response among patients has not been identified. The vast majority of patients - $29(78.38 \%)$ found a lack of a pattern of behavioral cognitive and emotional responses that would undoubtedly favor a certain type of internal picture of the disease. Only 8 patients (21.62\%) were diagnosed with a specific type of response: twice Apathetic and Harmonic, on one occasion Anosognostic, Euphoric, Hypochondriacal and Paranoid. An external locus of control has been identified, which is a sign of non-constructive adaptation.

The LOBI questionnaire lacks a block of "attitude to treatment" questions, which makes it impossible to describe patients' attitude to treatment using chronic HD. We assume that the internal picture of the disease is simultaneously shaped by the disease itself, renal failure as a complication, and treatment with chronic HD. The HD procedure is "life-saving" on the one hand for the patient, on the other - in itself dangerous and unpleasant (risk of contracting viral hepatitis). Therefore, the internal picture of the disease is the sum of the attitude to the disease and ambivalent reactions to treatment with chronic HD. This fact explains the results of the study: non-specific type of response to the disease.

Consider the most common answers to the Bechterev's Institute questionnaire: 14 (37.84\%) of patients say they do not allow themselves to be sad, which they cannot explain, 27 (72.97\%) patients are interested in food only as a means of maintaining health. 17 (45.95\%) patients answered that they try not to show their friends and relatives how sick they are, not to upset them, and the same number try to make it less burdensome for their relatives because of illness. 14 (37.85) patients try to prevent others from noticing their illness, $11(29.73 \%)$ believe that the disease does not interfere with friendship, 14 (37.85\%) avoid loneliness, without thinking about the disease, in 7 (18.92\%) insomnia was found, the reasons they cannot explain, $6(16.22 \%)$ confess that they are in constant anxiety for their future. Concerning the attitude to the medical staff $-19(51.35 \%)$ of the respondents consider attending to the patient the main feature of the medical worker, $11(29.73 \%)$ respect the medical profession, $4(10.81 \%)$ admit that doctors often feel unpleasant, $3(8.10 \%)$ believe that they are ill due to doctors.

It should also be noted that a personal questionnaire of the Bechterev's Institute for Diagnosis of the Disease Type allows to evaluate only the conscious component of the personality related to the disease interpersonal relationships and vital functions, and in HD patients it is noted according to our trend. Therefore, patients are not always able to identify and verbalize their condition, which complicates the diagnosis of the internal picture of the disease with the help of the LOBI. The components of the disease response are hidden deep beyond the conscious, where there is no access to conscious memory and thinking. In addition, some patients admit that they are in constant anxiety for their future, some note insomnia, which they cannot explain. This suggests the manifestation of unconscious mechanisms of adaptation to the disease. Therefore, we have chosen the projective method of diagnosis. Image the apperceptive test as a technique that allows us to reveal deep internal conflicts and features of mechanisms of adaptation to them.

\section{Image apperception test}

Patients were offered a series of drawings to identify the most common behavioral patterns and positions. The following questions were answered to the pictures, which were to be answered by the researched:

1. What happens in the picture?

2. Where are you here?

3. What are you doing?

The vast majority of patients imagined themselves fleeing rather than catching up, leaving the situation rather than interacting.

I - "run", "leave", "went and offended", "went round the corner", "contemplate", "stay away", "observe", "walk away", "do not pay attention". In a situation involving unequal spatial positions of people (for example, one person stands above another), the vast majority of patients described their location in the "above" position, imagining the situation "it is not me below." The questions you do are answered as follows: "I call the nurse", "I look indifferent", "I help the person" and so on. 
Therefore, the following psychological adaptation mechanisms are distinguished on the basis of the worked diagnostic material:

23 patients $(62.16 \%)$ were diagnosed with the negation of their condition,

25 patients $(67.57 \%)$ - displacement,

$3(8.11 \%)$ - rationalization,

$1(2.70 \%)$ - regression.

Note. The sum is more than $100 \%$, because there are several adaptation mechanisms.

Therefore, the data presented above indicates that patients have signs of adaptive mechanisms of denial and displacement. The constructiveness of these mechanisms can be determined by assessing levels of subjective control and anxiety.

Evaluation of the level of subjective control

$30(81.08 \%)$ patients were diagnosed with a low level of internality, i.e. an external locus of control. This indicator is a sign of unfavorable adaptation to HD therapy, as the responsibility for the treatment and subsequent life of the patient rests entirely on the outside world: relatives, medical staff, coincidence, etc. The sign can be manifested in the refusal of diet, water balance, medication, hospitalization, and requires psycho-corrective interventions.

Table 3. Level of subjective control in HD patients

\begin{tabular}{|l|c|c|c|}
\hline & \multicolumn{2}{|c|}{ General internality in patients (n=37) } \\
\cline { 2 - 4 } & Low & Moderate & High \\
\cline { 2 - 4 } & $30(81.08 \%)$ & $5(13.51 \%)$ & $2(5.41 \%)$ \\
\hline Source: Authors
\end{tabular}

\section{Recommended psychological counselling}

Psychological counselling of high level of situational anxiety during the HD procedure

Psychological counselling includes correction of the emotional state during the procedure of HD by distraction. Listening to music, watching movies, light physical exercises, group psychotherapy sessions, autogenic training, suggestive psychotherapy are recommended.

Correction of Decompensated Fear of Death:

We recommend the next psychological measures:

- individual psychotherapy (suggestive, tanatotherapy);

- group counselling (thematic training "Fear of Death", mutual support groups);

- bibliotherapy (for example, I.Yalom, "Staring at the Sun: Overcoming the Terror of Death"(Yalom, 2008));

- psychological counseling.

The above psychological characteristics of patients actualize the protective mechanisms of the identity of the health care provider, which are manifested in communication with patients. Patients, in turn, feel this influence and perceive it as negativity towards them. This is exacerbated by their own negativity, caused primarily by addiction to HD therapy and medical staff, which is also manifested in communication with health care providers. This creates a vicious circle in communication between patients and medical staff, which complicates compliance significantly. Reducing the tension in communicating with patients is already achieved at the stage when healthcare professionals understand that negativity and aggression on the part of patients are not directed at them as individuals and professionals. And patients are thus protected from the psychological traumatic situation they encountered in the transition to treatment with chronic HD.

Correction of dominant mechanisms of protection of the psyche

Psychotherapeutic work should be aimed at broadening the understanding of adaptive methods and their flexible application. Basically, the methods of rational and long-term group counselling are used. Correction of the dominant mechanisms of the psyche protection is necessary only in cases where the latter lead to:

1. High levels of situational or personal anxiety resulting from the inflexible use of displacement.

2. Maladaptive reactions when interacting with healthcare providers. 
3. A non-constructive approach when choosing a lifestyle, work-rest mode, diet, etc.

That is, a correction is needed only when the "adaptation" is maladapted.

As for the medical staff, the reduction of tension in communication with patients is reached already at the stage when health workers realize that the negativity and aggression on the part of patients is not directed at them as individuals and specialists, and patients are thus protected from the psychological traumatic situation they encountered when switching to chronic HD treatment.

\section{Conclusions}

Adaptation of the patient to HD therapy is complicated due to the high degree of anxiety and maladaptive terror of death, which reduce the patient's quality of life and adversely affect the stabilization of the somatic state. The HD procedure increases the level of situational anxiety and requires psychocorrection. HD therapy requires activation of the patient's psychological protection mechanisms, since the dominant protective mechanisms of the psyche in this type of substitution treatment are displacement and negation.

The inflexible and rigid use of the latter provokes maladaptive reactions when interacting with healthcare providers, a non-constructive approach to lifestyle choices, work-rest regime, and diet. The vast majority of patients are diagnosed with an external locus of control, which is a sign of unfavorable adaptation to HD therapy and require psychotherapy assistance.

Working with patients on HD leads to high risk of emotional burnout syndrome and professional deformity in the medical staff of HD units, so there is a need to monitor the psychological status of not only patients, but also medical staff, which due to the specificity of the contingent increases the level of contingent own terror of death. Doctors of HD units require participation in mutual support groups.

\section{References}

Aronow, E., Weiss, K. A., \& Reznikoff, M. (2013). A practical guide to the Thematic Apperception Test: The TAT in clinical practice: Routledge.

El Filali, A., Bentata, Y., Ada, N., \& Oneib, B. (2017). Depression and anxiety disorders in chronic hemodialysis patients and their quality of life: A cross-sectional study about 106 cases in the northeast of morocco. Saudi J Kidney Dis Transpl, 28(2), 341-348. doi:10.4103/1319-2442.202785

Javadi-Pashaki, N., \& Darvishpour, A. (2019). Survey of stress and coping strategies to predict the general health of nursing staff. J Educ Health Promot, 8, 74. doi:10.4103/jehp.jehp_355_18

Lee, V. L., \& King, A. H. (2014). Exploring Death Anxiety and Burnout Among Staff Members Who Work In Outpatient Hemodialysis Units. Nephrol Nurs J, 41(5), 479-485, 518.

Lichko, A. (1983). Lichnostnyy oprosnik Bekhterevskogo instituta (LOBI) [Personality Questionnaire of the Bekhterev Institute]. Metody psikhologicheskoy diagnostiki i korrektsii v klinike. Leningrad: Meditsina [Methods of psychological diagnosis and correction in the clinic. Leningrad: Medicine], 312.

McClellan, W. M., Anson, C., Birkeli, K., \& Tuttle, E. (1991). Functional status and quality of life: predictors of early mortality among patients entering treatment for end stage renal disease. J Clin Epidemiol, 44(1), 83-89. doi:10.1016/08954356(91)90204-m

Roeh, A., Kirchner, S. K., Malchow, B., Maurus, I., Schmitt, A., Falkai, P., \& Hasan, A. (2019). Depression in Somatic Disorders: Is There a Beneficial Effect of Exercise? Front Psychiatry, 10, 141. doi:10.3389/fpsyt.2019.00141

Spielberger, C. D. (1983). State-trait anxiety inventory for adults.

Wallston, B. S., Wallston, K. A., Kaplan, G. D., \& Maides, S. A. (1976). Development and validation of the health locus of control (HLC) scale. J Consult Clin Psychol, 44(4), 580-585. doi:10.1037//0022-006x.44.4.580

Yalom, I. (1980). Existential Psychotherapy. N.Y.: Basic Books.

Yalom, I. (2008). Staring at the sun: Overcoming the terror of death. The Humanistic Psychologist, 36(3-4), $283-297$.

Yalom, I., \& Lieberman, M. (1991). Bereavement and heightened existential awareness. Psychiatry, 54(4), 334-345. doi:10.1080/00332747.1991.11024563

Zamanayeva, Y., \& Frumkin, A. (2005). Psikhologicheskaya pomoshch' meditsinskomu personalu: postanovka problem i vozmozhnyye puti resheniya [Psychological assistance to medical personnel: statement of problems and possible solutions]. Informatsionnyy byulleten' dlya vrachey gospital'nykh epidemiologov, organizatorov zdravookhraneniya $i$ vrachey drugikh spetsial'nostey. \{Information bulletin for doctors of hospital epidemiologists, healthcare organizers and doctors of other specialties.]-St. Petersburg, $2005-18$ p. 